\title{
SHARED SPACE IS HUMAN TECHNOLOGY
}

DOI: 10.18485/arh_pt.2020.7.ch4

\author{
_ Pieter de Haan \\ Consultant, researcher Knowledge Centre Shared Space Westersingel 4 \\ 8913CK Leeuwarden, Netherlands, pieter@kenniscentrumsharedspace.nl
}

\section{ABSTRACT}

In the Dutch city of Drachten over 20 years ago a project started to design a junction without traffic signs nor lines and with a single surface level. Later on it was called Shared Space and this concept started to spread over the Netherlands and surrounding countries.

Background for this idea was that, certainly in old city centres and villages, technology was not enough to acquire the behaviour that was preferable. More and more rules were violated and respect and communication between road users was decreasing. An overview of these years can be found in an article in Urban Design (De Haan, 2018).

After experiments and evaluations of many projects we now know that there is more needed to reach a working Shared Space. A place should be related to the history of the place or neighbourhood. Places are unique in a historical way, but have also a social meaning. So every Shared Space location is unique and depending on the design it will have the results of a place that has more quality and is more vibrant, lively.

If we (the designers) can design places in a way that more human behaviour is elicited, then places are no longer traffic places, but social places, places to be, to shop and to meet. This is what happens in Shared Space.

People communicate with other road users all equal in their rights, no longer dependent nor defined by the mode of transport they use or the place they use. Speeds are harmonized and low. The technology used for this is design, urban design, architecture. Perception based on psychological principles and risk balance in adapting speeds.

In the conference we now can present results of experiments and evaluative studies on Shared Space. It's no longer an idea, but a concept that's becoming based on scientific results and data.

KEYWORDS _ shared space, urban design, human technology

\section{INTRODUCTION: TECHNOLOGY IN THE PUBLIC SPACE}

A facial recognition system is pure technology, trying to copy a human ability to recognize people by their faces. But humans can do more, they see emotions, non verbal expressions and combine them also with voices, places, gestures etc. This "technology" is not only a human ability, also most animals can do the same.

Public spaces are the places where this human capability is needed to cope with the surrounding and other humans.

More and more the motorised traffic becomes a technology driven way of mobility. Electric cars, lane keeping systems, automatic braking, intelligent speed adaptation and self driving cars are prom- 
ising features in the public space. Artificial Intelligence is a phenomenon that's becoming a main and basic instrument to control and manage lots of systems. Junctions where traffic lights rule the traffic flow of people, in cars walking and cycling. And what happens when the traffic lights don't work because of a electric outage? Most times it flows also, maybe a bit slower and certainly in more chaos, but the road users rely then on the communication with each other, also an aspect of human technology.

But most road users are walking or biking, without all of these means of travelling. They rely on own decisions, made on habits, intuition, rapid perception and cognition. From a car driver's point of view car-driving looks safe, but we see that most of the (fatal) incidents, all over the world, happen amongst pedestrians and cyclists. More than half of all road traffic deaths are among vulnerable road users: pedestrians, cyclists and motorcyclists (Global status report on road safety, 2018). And from the vulnerable road users, the children are a big proportion of this number. As the report says: Road traffic injuries are now the leading cause of death for children and young adults aged 5-29 years.

Globally over 270,000 pedestrians are killed each year, one fifth of all death in traffic (World Health Organization Geneva).

Maybe the systems in the public space need not only a technical but also a "human" touch. As a parallel human technology could be an important contribution to make places more safe, places to be and even more social.
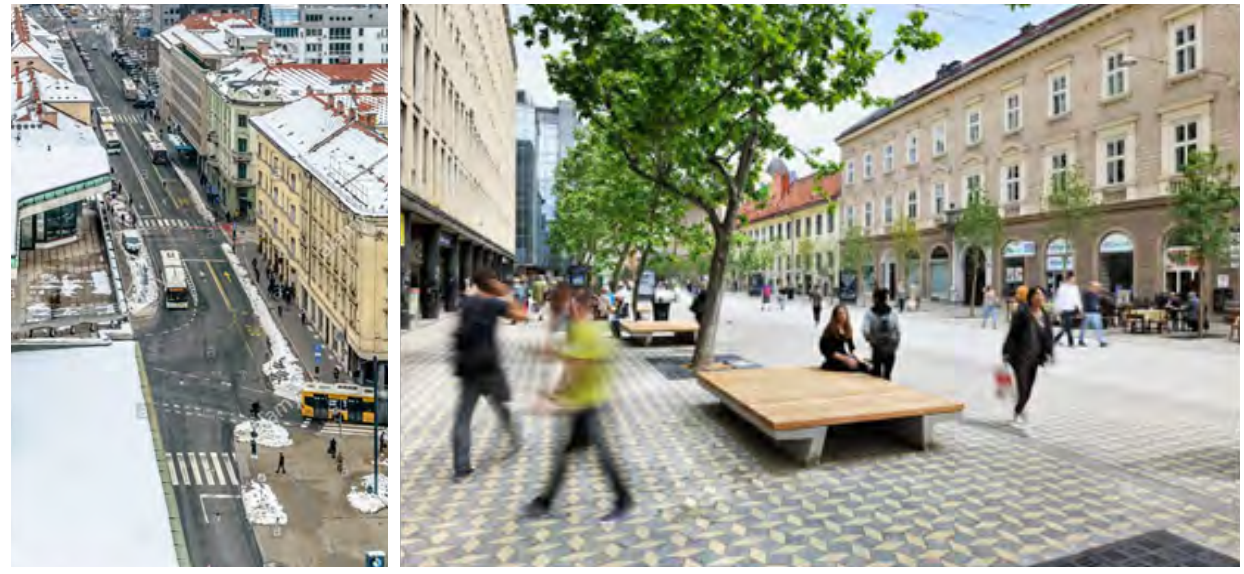

_ Figure 1: Ljubljana, Slovenska cesta before and After

\section{PSYCHOLOGICAL BACKGROUND FOR HUMAN TECHNOLOGY}

Humans make decisions all day, with small or big impact on their own life and most times of others. The way of decision making is a wide and thorough researched field of science. Pavlov (Pavlov, 1927) and Skinner (Skinner, 1938) started with the way how organisms, later confirmed for humans, decide to decide. Rewards and penalties were the main engine to do things. This was the start of behaviourism. Just looking at the outside to see what organisms do. It was Maslow (Maslow, 1954) who made human motivation clear as a motor for behaviour.

The decision-making they studied was more or less based on considered possibilities. These decisions take time, looking at the pro's and con's. "Where do we go on holiday?", "Is this house suitable?"

But in every day life, certainly in traffic, we have a quite different task. Reacting on all the input, the input of signs, stimuli we have to look at, understand, react toor ignore. 
We use simple heuristics to make decisions when in a hurry or just because there is no time to overlook all the options. We use them also when the decision has not a big impact, as far as the consequences are known. It was Herbert A. Simon (Simon, 1982) who came up with his model of Bounded Rationality. In this theory he labelled this process "satisficing" and concluded that human decision-making could at best exhibit bounded rationality. Although objective rationality leads to only one possible rational conclusion, satisficing can lead to many rational conclusions, depending upon the information available and the imagination of the decision maker (Munro and Nitta, 2013). But: "This vision 0 has two interlocking components: the limitations of the human mind, and the structure of the environments in which the mind operates.", says Gerd Gigerenzer (Gigerenzer, 1999). Certainly Simon was the one that predicted the possibilities of Artificial Intelligence, as computers can calculate all the options. And in a very short time. When a human is called Homo Economicus, then we talk about the person that calculates the pro's and cons and decides. But look in traffic behaviour. A complicated task that's most times too complicated. Certainly in crowded places where lots of stimuli ask for attention. Then we have to choose, and on a basis that we hardly know. We only can see that accidents happen when there are too many tasks - using a phone while driving and even commercial advertisements distract the driver from the right and quick choice.

This is what happens with behaviour in public spaces. Road users, normally don't have time to calculate the possible options they have, because of speed, hurry, complicated environments and distraction, because of tasks and social surrounding.

What happens then? The organism looks for an optimal strategy, lets call it "best guess".

Gigerenzer says that one-cue decisions are almost the second best after the economic consideration of alternatives. Most times there are more cues to base a decision on, but it's the choice of cues that's most times not known, not by an objective observer and even most times not by the pedestrian or cyclist himself.

So to make decision-making better in complicated situations, and the urban environment is most times a complicated situation, we need to make decision-making simpler. In cars, devices do already help the driver concentrate on real random-happening tasks, while the system takes over routines and controls.

For cyclists and pedestrians we need to look at the other part of the interlocking components, the structure of the environment. But not only that, we know that the human brain can do much more, including beliefs, emotions and needs when it makes decisions. They react on each other. They communicate, visual, non-verbal and have routines.

That's what we do in Shared Space.

\section{SHARED SPACE AS A HUMAN SPACE FOR DECISION-MAKING}

One of the first projects for applying the ideas of Shared Space was at the Laweiplein square in the City of Drachten in the Netherlands. This is a sort of round about, but the design differs from standard design, lacking zebras and clear ways of priority. So, on first observation we saw cyclists, certainly also the young ones, school children, giving hand signs. Much more than in traditional regulated locations. This was a first indication that the environment did not rule the behaviour in a strict way but made road users communicate with others. Later students from the Groningen University did a research on this phenomenon and found out that in Shared Space locations, compared to regulated locations, there were more non-verbal signs (Vries-Koopmans, 2013) In Figure 1, the red-dotted line shows a higher average of communicative acts than in the two other places. We see the most acts in situations with an average traffic flow.

It looks as if the lack of signs from the system urges road users to communicate with each other instead of with the system This form of communication is not how we normally comprehend it, because it's just one way communication. Shared space system stimulates and enables 2-way communication without additional infrastructure!

The observation and the research was an indication that the late Hans Monderman was right that it 
all deals with communication in traffic.

But is it good for all road users? Along the introduction of Shared Space in many places, not only in the Netherlands, where it started, in the 1990s, but in Europe in almost every country and in places in other continents. The concept of Shared Space strives to make the public space for all humans accessible and with the same rights.
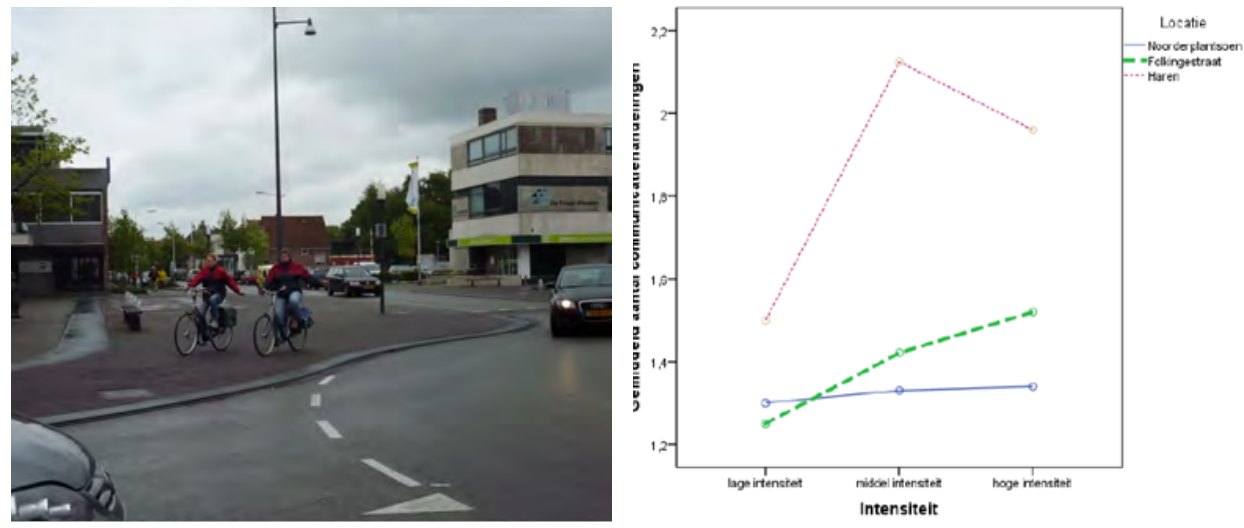

_ Figure 2: Signing by cyclists and number of gestures

\section{SHARED SPACE FOR EVERY HUMAN?}

Questions have come up, about vulnerable road users, like blind and visually-impaired people, who don't have the ability to communicate with vision. Making a street design in one level, without sidewalks and curbs, would give problems for blind people to orientate, but wheelchairs could move easier.

A research done by Else Havik (Havik, 2012) comparing three conventional locations with Shared Space places revealed that there were no significant differences between locations when asked about the feeling of unsafety. In Shared Space we find most times people reporting that they felt unsafe, when "their" place was reconstructed into a Shared Space. But when asked more in-depth it was more a feeling of "insecurity", not knowing what to do, because there was no clear guidance. Older people reported this more than younger ones. After a certain time we saw this feeling diminishing and also avoiding those places became less frequent. In the research of Else Havik, when blind and visually impaired people had to walk a pattern through the place, the result was that in one of the Shared Spaces, they got lost, problems with way-finding and orientation. A closer look at that place learned that the design, could be done better, with more points that could serve as orientation points. So we made a guidance for local designers, together with the Knowledge Institute for the Blind. And for the blind and visually-impaired road users, new developments are coming, developments that can help them move through Shared Space (See https://www.visio.org/ en-gb/professional/bevordering-deskundigheid/vision-2017/visio-presentations-at-vision-2017 or https://www.technologyreview.com/s/613632/these-colorful-stickers-are-helping-blind-people-find-their-way-around/).

A better application is the use of Galileï. This can guide blind and visually impaired people. It's much more precise than GPS, and that's important to find one's way in public space. It's not ready yet but it's a promise for future orientation for the blind and visually impaired.

But apart from all this technology, there is also the social way. When people can show their need, to cross the street or to find their way, they can ask and I saw, in may cases, that this form of communication works well.

Shared Space is for every road user and gives each the same rights not depending on the mode of 
transport or where they are in the public space. It needs a responsible and creative input from the designing engineers for the vulnerable road user. In the years that the Knowledge Centre grew in experience we could make together with Royal Visio an expertise centre for visually impaired and blind-people-guidelines regarding these road users (Havik and Melis-Dankers, 2014).

\section{SHARED SPACE ACCEPTED AS URBAN DESIGN TECHNOLOGY}

After the concept became a viable option to use in urban design, no longer the ideas of Hans Monderman were the only source, although he brought these concepts with a lot of charisma. Still more research became required: figures, measurements, and experiments. Besides that, the concept and realisation lacked a process in the beginning and an evaluation afterwards. This was added by the Knowledge Centre Shared Space: Functional ambiance as a method to assess the situation and to formulate the ambition (http://www.urbanisten.nl/wp/?portfolio=functional-ambiance- 2 visited February 23,2020 .). From this we now know that these parts are essential to realise a project that's a project for the users, the people around that space. These projects are no longer suspect as only coming from "the engineers and the politicians". A peoples place is almost "owned" by the people, it's their square, village centre or street.
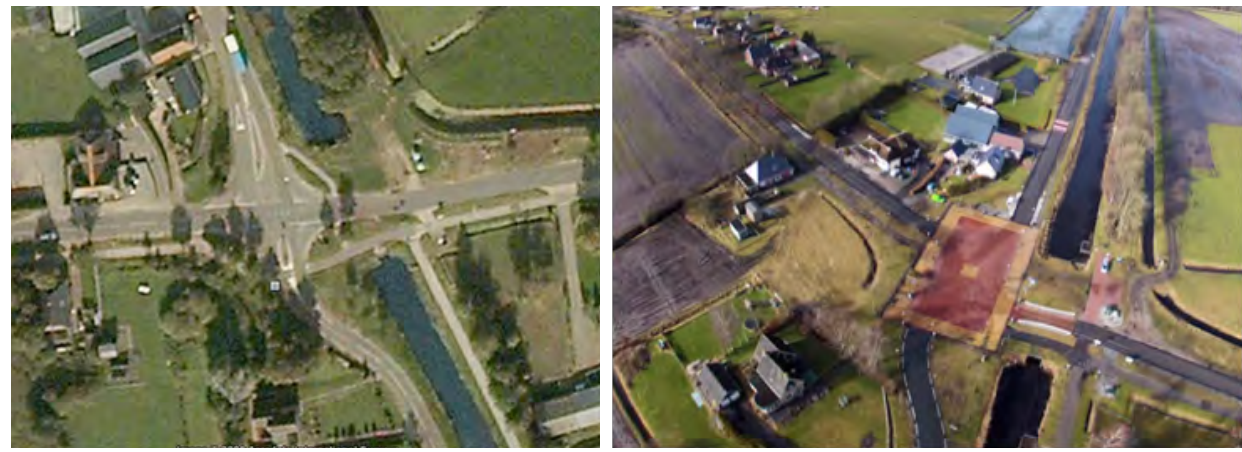

_ Figure 3 (left): Before and Figure 4 (right): After reconstruction (Pictures Google Earth)

At this junction in the village of Siegerswoude, The Netherlands, there were severe accidents, driving too fast and even a fatal one. Engineers suggested a roundabout. That's a technological solution, also an easy one, a copy of the many roundabouts everywhere. But the villagers wanted something better, something of their own and together with a group and help of the shared space workers, another design was made, a square in a rural surrounding. No straight roads anymore, a place a bit hidden with trees and bushes, so speeds go down and only on the square a road user can find it's way. It works, it's found much nicer and even some functions could be added. This place got an identity, the villagers named it "Ons dorpsplein" ("our village square").

So here we see that with human intelligence it's possible for people to reach their own solutions for their own problems. These solutions will have support and less (or no) objections, because they are from bottom up and therefore also sustainable.

\section{CONCLUSIONS}

"Is there a definition for Shared Space?" A question many times heard.

But a definition suggests that Shared Space is a standard solution, a concept to apply everywhere and always with the same look. This is not what it should be. So in the run of over 20 years we found 
out that it's better to find conditions for applying Shared Space.

_ A place is suitable for Shared Space when there are more functions than just moving from A to B.

- The place or places should be part of a network with a higher hierarchy.

- Speeds should be harmonized, with design measures.

- Shared Space needs a design process that includes the community and their evaluation.

- The design should reflect the history of the place.

- The design characterises the identity of the place.

- The place is accessible for everyone.

And we can conclude that the concept of Shared Space is still a concept, never ready and there are still more questions to answer and more questions will be raised and researched.

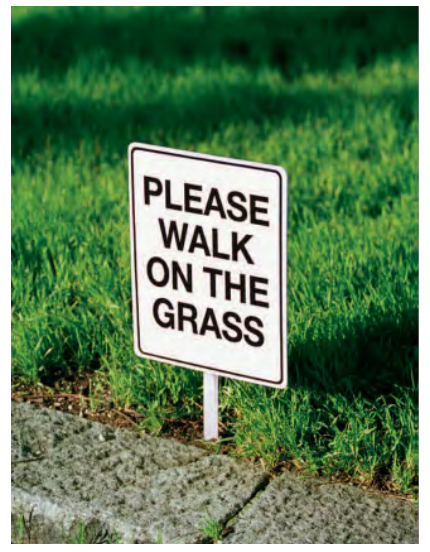

In search of a definition of shared space:

Public space is all around us, a vital part of everyday urban life: the streets we pass through on the way to school or work, the places where children play, or where we encounter nature and wildlife; the local parks in which we enjoy sports, walk the dog and sit at lunchtime; or simply somewhere quiet to get away for a moment from the bustle of a busy daily life. In other words, public space is our open-air living room, our outdoor leisure centre.

_ Figure 5: A short(left) and a longer definition of Shared Space

\section{REFERENCES}

_ De Haan, P, in 147 Urban Design, Summer 2018, Urban Design Group Journal, , ISSN 1750 712X Streetscape

_ Global status report on road safety 2018: summary. Geneva: World Health Organization; 2018 (WHO/ $\mathrm{NMH} / \mathrm{NVI} / 18.20)$. Licence: CC BY-NC-SA $3.0 \mathrm{IGO}$

_ Pedestrian Safety, A road safety manual for decision-makers and practitioners, World Health Organization Geneva 27 Switzerland

_ Pavlov, L.P. (1927) Conditioned reflexes Oxford: Oxford University Press.

- Skinner, B.E. (1938) The Behaviour of Organisms, New York: Appleton Century-Crofts.

_ Maslow, A. (1954), Motivation and Personality. New York: Harper \& ROW.

_ Simon, H.A. (1982) Models of bounded rationality, Cambridge, MA: MIT Press.

_ André Munro and Keith Nitta, 2013 Decision Making, Encyclopedia Brittanica.

_ Gigerenzer, G, Peter M. Todd, 1999, Simple Heuristics That Make Us Smart, Oxford University Press.

_ Vries-Koopmans, K.de, 2013, Communication and Traffic: Shared Space, University of Groningen.

_ Havik, E, 2012, Wayfinding and Accessibility for visually impaired people. Wöhring Printservice Zutphen, ISBN 978-90-367-5733-1

_ Havik, E. and Melis-Dankers J.M. 2014, "Toegankelijkheid van Shared Space gebieden voor blinde en slechtziende mensen", Koninklijke Visio Huizen, The Netherlands

- http://www.urbanisten.nl/wp/?portfolio=functional-ambiance-2 visited February 23, 2020. 